\title{
Adverse Events of Thiopurine Therapy in Pediatric Inflammatory Bowel Disease and Correlations with Metabolites: A Cohort Study
}

\author{
Jasmijn Z. Jagt ${ }^{1} \cdot$ Christine D. Pothof $^{1} \cdot$ Hans J. C. Buiter ${ }^{2} \cdot$ Johan E. van Limbergen $^{3} \cdot$ Michiel P. van Wijk $^{1,3}$. \\ Marc A. Benninga ${ }^{3} \cdot$ Nanne K. H. de Boer ${ }^{4}$ Tim G. J. de Meij ${ }^{1,3}$
}

Received: 6 November 2020 / Accepted: 7 January 2021 / Published online: 3 February 2021

(c) The Author(s) 2021

\begin{abstract}
Background In the recent era of growing availability of biological agents, the role of thiopurines needs to be reassessed with the focus on toxicity.

Aims We assessed the incidence and predictive factors of thiopurine-induced adverse events (AE) resulting in therapy cessation in pediatric inflammatory bowel disease (IBD), related to thiopurine metabolites and biochemical abnormalities, and determined overall drug survival.

Methods We performed a retrospective, single-center study of children diagnosed with IBD between 2000 and 2019 and treated with thiopurine therapy. The incidence of $\mathrm{AE}$ and overall drug survival of thiopurines were evaluated using the Kaplan-Meier method. Correlations between thiopurine metabolites and biochemical tests were computed using Spearman's correlation coefficient.

Results Of 391 patients with IBD, 233 patients (162 Crohn's disease, 62 ulcerative colitis, and 9 IBD-unclassified) were prescribed thiopurines (230 azathioprine and 3 mercaptopurine), of whom 50 patients (22\%) discontinued treatment, at least temporary, due to thiopurine-induced AE (median follow-up 20.7 months). Twenty-six patients (52\%) were rechallenged and 18 of them (70\%) tolerated this. Sixteen patients (6\%) switched to a second thiopurine agent after azathioprine intolerance and 10 of them (63\%) tolerated this. No predictive factors for development of AE could be identified. Concentrations of 6-thioguanine nucleotides (6-TGN) were significantly correlated with white blood cell and neutrophil count, 6-methylmercaptopurine (6-MMP) concentrations with alanine aminotransferase and gamma-glutamyltranspeptidase.

Conclusions Approximately $20 \%$ of pediatric patients with IBD discontinued thiopurine treatment due to AE. A rechallenge or switch to mercaptopurine is an effective strategy after development of AE. Concentrations of 6-TGN and 6-MMP are associated with biochemical abnormalities.
\end{abstract}

Keywords Thiopurines $\cdot$ Pediatrics $\cdot$ Inflammatory bowel disease $\cdot$ Adverse events $\cdot$ Metabolites

\section{List of symbols}

6-MMP 6-methylmercaptopurine

6-TGN 6-thioguanine nucleotides

AE Adverse event(s)

ALT Alanine aminotransferase

ANC Absolute neutrophil count

AP Alkaline phosphatase

AST Aspartate aminotransferase

AZA Azathioprine

Guarantor of the article: Jasmijn Jagt.

Jasmijn Z. Jagt

j.jagt1@amsterdamumc.nl

Extended author information available on the last page of the article

$\begin{array}{ll}\text { CD } & \text { Crohn's disease } \\ \text { GGT } & \text { Gamma-glutamyltranspeptidase } \\ \text { IBD } & \text { Inflammatory bowel disease } \\ \text { IBD-U } & \text { Inflammatory bowel disease unclassified } \\ \text { IFX } & \text { Infliximab } \\ \text { IQR } & \text { Interquartile ranges } \\ \text { MCV } & \text { Mean corpuscular volume } \\ \text { MP } & \text { Mercaptopurine } \\ \text { OR } & \text { Odds ratios } \\ \text { UC } & \text { Ulcerative colitis } \\ \text { WBC } & \text { White blood cell }\end{array}$




\section{Introduction}

The immunomodulating thiopurine drugs, including azathioprine (AZA) and mercaptopurine (MP), are frequently used in pediatric inflammatory bowel disease (IBD), both as maintenance monotherapy and in combination with infliximab to reduce the risk of formation of anti-IFX antibodies, and to increase efficacy [1-3]. Their efficacy in maintaining remission was demonstrated in several observational studies $[4,5]$ and in one RCT in children with IBD [6]. However, the role of thiopurines has become debatable due to contradictory results on efficacy in adults with Crohn's disease (CD) on the one hand [7, 8], and safety concerns on the other $[1,2,9]$. In the recent era of growing availability of different biologic agents, there is need for reassessment of thiopurines with the focus on toxicity.

Several studies provide data regarding thiopurineinduced adverse events (AE) in the pediatric IBD population, reporting discontinuation rates due to $\mathrm{AE}$ varying between 10 and 22\% [5, 10-13]. However, most studies were characterized by a small sample size and the main objective in the majority of these studies was to assess the efficacy, but not safety of this compound. Mercaptopurine may be considered as an alternative thiopurine agent in patients previously intolerant to AZA therapy [14, 15]. Most studies, however, have focused on adults with IBD.

This study aimed to determine incidence of thiopurineinduced AE resulting in cessation of therapy in a real-life pediatric IBD cohort. In addition, we aimed to evaluate the efficacy of rechallenge and switching to a second thiopurine in case of AE. Secondary aims were to identify predictive factors for $\mathrm{AE}$, to assess the correlation between thiopurine metabolites and biochemical tests, and determining overall drug survival of thiopurines.

\section{Materials and Methods}

\section{Study Design and Patient Population}

This retrospective, single-center cohort study was performed at the Amsterdam University Medical Center (location VUmc), the Netherlands. All children $<18$ years of age, diagnosed with IBD between January 1, 2000, and December 31, 2019, and were prescribed thiopurines, including AZA and MP, were included. The diagnosis of IBD (CD, ulcerative colitis (UC) or IBD-unclassified (IBD-U)) was based on endoscopic, radiologic, and histologic findings according to the revised Porto criteria [16] and classified according to the Paris classification [17].
Patients with bone marrow suppression or preexistent liver disease before initiation of thiopurine therapy or a followup less than three months were excluded from analysis. Patients were followed for a maximum of eight years or until cessation of thiopurine therapy.

\section{Data Collection}

The following patient characteristics were collected: gender, weight, height, IBD type, age at diagnosis, time (in months) since IBD diagnosis until initiation of thiopurine therapy, and small bowel surgery prior to thiopurine treatment. Furthermore, type of thiopurine (AZA or MP), date of initiation of thiopurine, age at initiation of thiopurine, thiopurine dose, and duration of thiopurine use were collected. Thiopurines were prescribed according to the ECCO/ESPGHAN guidelines (AZA dose of $2-2.5 \mathrm{mg} / \mathrm{kg}$ or a MP dose of $1-1.5 \mathrm{mg} /$ $\mathrm{kg})[1,2]$. Thiopurine methyltransferase (TPMT) genotyping and activity assessments were not routinely assessed. The use of concomitant anti-TNF $\alpha$ agents was documented. Concentrations of 6-thioguanine nucleotides (6-TGN) and 6-methylmercaptopurine (6-MMP) measured routinely 8-16 weeks after initiation of thiopurine therapy, were collected. In patients who ceased therapy due to AE, concentrations of 6-TGN and 6-MMP were collected within the interval of maximum 4 months before cessation.

\section{Adverse Events}

An $\mathrm{AE}$ was defined as any noxious or unintended response that occurred during the course of treatment, considered to be thiopurine-induced, and resulting in cessation of thiopurine therapy. The decision to stop treatment, rechallenge, or switch to another thiopurine compound was based on the treating physician's judgement, together with the patient and/or the parents. AE were graded in severity according to The Common Terminology Criteria for Adverse Events (CTCAE) (Version 5.0, released November 27, 2017) [18]. The CTCAE are a set of criteria for the standardized classification of AE using a range of grades from 1 to 5 (1: mild, 2: moderate, 3: severe, 4: life-threatening and 5: adverse event-related death). AE were subdivided into leukopenia, neutropenia, thrombocytopenia, myelotoxicity, hepatotoxicity, flu-like symptoms, gastrointestinal symptoms, pancreatitis, and others. Definitions are depicted in Table 1.

\section{Thiopurine Metabolites and Laboratory Measurements}

To assess the association between thiopurine metabolites and hematological indices and liver tests, the therapeutic drug monitoring database of the department of clinical pharmacology was scrutinized for available thiopurine metabolite 
Table 1 Definitions of thiopurine-induced adverse events

\begin{tabular}{ll}
\hline Adverse Event & Definition \\
\hline $\begin{array}{l}\text { Moderate leukopenia } \\
\text { Severe leukopenia }\end{array}$ & White blood cell count $<3.0 \times 10^{9} / \mathrm{L}$ \\
Neutropenia & Abite blood cell count $<2.0 \times 10^{9} / \mathrm{L}$ \\
Thrombocytopenia & Platelet count $<150 \times 10^{9} / \mathrm{L}$ \\
Myelotoxicity & Suppression of the bone marrow activity leading to anaemia (hemoglobin concentration $<2.5$ th percentile for age), \\
& leukopenia, and thrombocytopenia \\
Hepatotoxicity & Twice or more the upper limit of ALT, AST, AP, or GGT \\
Flu-like symptoms & General malaise, fever, and muscle and joint pain \\
Gastrointestinal symptoms & Nausea and vomiting \\
Pancreatitis & Severe abdominal pain accompanied with a rise in serum lipase levels three times above the upper limit of normalcy \\
Others & Includes infection and nonspecific side effects, such as headache, asthenia, or other symptoms during treatment \\
& necessitating cessation of thiopurine therapy \\
\hline
\end{tabular}

$A L T$ alanine aminotransferase, $A S T$ aspartate aminotransferase, $A P$ alkaline phosphatase, $G G T$ gamma-glutamyltranspeptidase

measurements. All laboratory measurements within a timeframe of 3 days before or after thiopurine metabolite measurement were included. The reported laboratory measurements included: hemoglobin concentration $(\mathrm{Hb})$, white blood cell (WBC) count, mean corpuscular volume (MCV), absolute neutrophil count (ANC), platelet count, alanine aminotransferase (ALT), aspartate aminotransferase (AST), alkaline phosphatase (AP), and gamma-glutamyltranspeptidase (GGT). In this sub-analysis, hepatotoxicity was defined as $>$ twice upper limit of ALT, AST, AP, or GGT; myelosuppression as either WBC below $3.0 \times 10^{9} / \mathrm{L}$ or PC under $150 \times 10^{9} / \mathrm{L}$ or ANC below $1.5 \times 10^{9} / \mathrm{L}$, not necessarily resulting in thiopurine cessation.

The concentrations of 6-TGN and 6-MMP in our center were determined in red blood cells, using a high-performance liquid chromatography method modified from Dervieux et al. [19]. The lower limit of detection was $30 \mathrm{pmol} / 8 \times 10^{8} \mathrm{RBC}$ for 6 -TGN and $15 \mathrm{pmol} / 8 \times 10^{8} \mathrm{RBC}$ for 6-MMP, whereas the lower limit of quantification was 70 and $100 \mathrm{pmol} / 8 \times 10^{8} \mathrm{RBC}$, respectively. According to hospital guideline, reference values are $300-600 \mathrm{pmol} / 8 \times 10^{8}$ $\mathrm{RBC}$ and $<5700 \mathrm{pmol} / 8 \times 10^{8} \mathrm{RBC}$ for 6-TGN and 6-MMP, respectively (according to the method of Dervieux).

\section{Drug Survival}

Drug survival was measured by calculating the number of patients on thiopurine therapy at 3, 6, 12, 24, and 60 months after initiation. Reasons for cessation of therapy were documented, including clinical refractoriness, sustained clinical remission, or at patients' or parents' own request. Patients with combination therapy of thiopurines and anti-TNF $\alpha$ agents in context of an anti-TNF $\alpha$-based top-down approach [1], and patients who ceased thiopurine therapy due to AE, were excluded from this analysis. Fecal calprotectin levels were collected in patients who continued thiopurine monotherapy until the end of follow-up period, to evaluate disease activity. Biochemical remission was defined as fecal calprotectin levels of $<250 \mu \mathrm{g} / \mathrm{mg}$, in samples available within 3 months from last follow-up visit.

\section{Statistical Analyses}

Statistical analyses were performed using the Statistical Package for Social Sciences (SPSS, IBM; v25). $P$ values $<0.05$ were considered to be statistically significant. For normally distributed data, both means and standard deviations were calculated, whereas medians and interquartile ranges (IQR) were calculated for data with a non-normal distribution. Data were compared using the Mann-Whitney $\mathrm{U}$ test for nonparametric continuous data and the unpaired $\mathrm{t}$ test for normally distributed data. Categorical variables were compared using the Chi-square test or Fisher's exact. The Kaplan-Meier method was used to evaluate the cumulative incidence of $\mathrm{AE}$ and overall drug survival. Logistic regression analyses were performed to investigate potential predictive factors for thiopurine-induced $\mathrm{AE}$ within 6 months after initiation. Variables reaching statistical significance $(p<0.2)$ were included in a multivariate regression analysis. The results were expressed as odds ratios (OR) with 95\% confidence intervals. Correlations between thiopurine metabolites and laboratory measurements were computed using Spearman rank correlation coefficient.

\section{Results}

\section{Patient Population and Baseline Characteristics}

A total of 391 pediatric patients were diagnosed with IBD in the predefined study period, and 245 children (62.7\%) used thiopurines at any moment following diagnosis. 
We excluded 12 patients: nine patients due to an insufficient follow-up and three patients refused to participate. The patient characteristics of the 233 included children

Table 2 Characteristics of pediatric patients with IBD managed with thiopurine therapy

\begin{tabular}{ll}
\hline & Total $(n=233)$ \\
\hline Median age at diagnosis, years [IQR] & $13.7[11.1-15.4]$ \\
Male, $n$ (\%) & $126(54.1)$ \\
Type of disease, $n(\%)$ & \\
CD & $162(69.5)$ \\
UC & $62(26.6)$ \\
IBD-U & $9(3.9)$ \\
Paris location of CD patients, $n(\%)$ & \\
L1: ileal & $32(19.8)$ \\
L2: colonic & $46(28.4)$ \\
L3: ileocolonic & $79(48.8)$ \\
Upper GI involvement: L4a, L4b & $43(26.5), 2(1.2)$ \\
Paris behavior of CD patients, $n(\%)$ & \\
B1: nonstricturing, nonpenetrating & $145(89.5)$ \\
B2: stricturing & $12(7.4)$ \\
B3: penetrating & $2(1.2)$ \\
B2B3: both penetrating and structuring & $3(1.9)$ \\
P: perianal disease modifier, $n(\%)$ & $40(24.7)$ \\
Paris location of UC patients, $n(\%)$ & \\
E1: ulcerative proctitis & $3(4.8)$ \\
E2: left-sided UC (distal splenic flexure) & $5(8.1)$ \\
E3: extensive (hepatic flexure distally) & $4(6.5)$ \\
E4: pancolitis (proximal hepatic flexure) & $50(80.6)$ \\
First type of thiopurine, $n$ (\%) & $230(98.7)$ \\
AZA & $3(1.3)$ \\
MP & $42[17-153]$ \\
Median time to start thiopurine, days [IQR] & $14.5[11.9-15.8]$ \\
Median age at start thiopurine, years $[\mathrm{IQR}]$ & $5(2.1)$ \\
Small bowel surgery, $n(\%)$ & \\
\hline
\end{tabular}

$C D$ crohn's disease, $U C$ ulcerative colitis, $I B D-U$ IBD-unclassified, GI gastrointestinal, $A Z A$ azathioprine, $M P$ mercaptopurine are depicted in Table 2. The median follow-up was 20.7 months [IQR, 6.0-42.1]. In the group of patients with AZA, the median start dose was $2.3 \mathrm{mg} / \mathrm{kg}$ [IQR, 2.1-2.5]. In patients using MP, the median start dose was $1.2 \mathrm{mg} / \mathrm{kg}$ [range, 1.2-2.4]. Forty-nine patients (21\%) received combination therapy with infliximab and AZA following diagnosis. The concomitant use of infliximab did not affect the thiopurine dose and concentrations of 6-TGN and 6-MMP.

\section{Adverse Events}

In total, 50 patients (21.5\%) developed thiopurine-induced $\mathrm{AE}$ leading to, at least temporary, cessation of therapy (Table 3 and 4). None developed grade 4 or 5 AE (i.e., life-threatening or adverse event-related death), malignancy, lymphoproliferative disorders or hemophagocytic lymphohistiocytosis (HLH). The median time of cessation of therapy due to AE was 57 days [IQR, 21-217] following initiation of thiopurines (Fig. 1).

Thiopurine therapy was restarted in 26 patients (52\%) who discontinued treatment due to presumed AE. The same thiopurine, mainly AZA, was reintroduced in 18 patients, while a second thiopurine agent was reintroduced in 8 patients ( $6 \mathrm{MP}, 2$ tioguanine). Of these 26 patients, eight patients (30.8\%) developed the same AE, resulting in complete cessation of therapy (Table 4). Furthermore, 9 out of 233 patients (3.9\%) switched directly (without cessation) from AZA to MP due to $\mathrm{AE}(n=8)$ or aberrant metabolite concentrations $(n=1)$. Amongst these eight patients with AE, reported AE were alopecia $(n=4)$, gastrointestinal symptoms $(n=2)$ and others $(n=2)$. Six of 8 patients $(75 \%)$ who switched directly from AZA to MP, could continue with MP therapy. In total, 10 out of 16 patients $(62.5 \%)$ who switched to a second thiopurine agent, did not experience the previously reported AE. Nineteen patients received allopurinol as co-medication, based on elevated 6-MMP concentrations.

Table 3 Adverse events $(n=50)$ leading to cessation of thiopurine therapy, listed, and graded according to the common terminology criteria (CTC)

\begin{tabular}{llll}
\hline Adverse event & Grade 1 (mild) $n=12$ & Grade 2 (moderate) $n=21$ & Grade 3 (severe) $n=17$ \\
\hline Blood, lymphatic and vascular disorders & Myelotoxicity, $n=1$ & - & $\begin{array}{l}\text { Severe leukopenia, } n=2 \\
\text { Myelotoxicity, } n=1 \\
\text { Thrombocytopenia, } n=1\end{array}$ \\
Gastrointestinal disorders & & & Pancreatitis, $n=7$ \\
General, neurological, and psychiatric disorders & Nausea, $n=5$ & Pancreatitis, $n=1$ & Vomiting, $n=1$ \\
Hepatobiliary disorders & Vomiting, $n=1$ & Vomiting, $n=9$ & Flu-like symptoms, $n=3$ \\
Infections and infestations & Hepatotoxicity, $n=1$ & Flu-like symptoms, $n=7$ & Hepatotoxicity, $n=2$ \\
Musculoskeletal and skin disorders & - & Shingles, $n=1$ & -
\end{tabular}


Table 4 Time of onset of the AE following initiation of thiopurine therapy and restart of thiopurine therapy in patients with thiopurine-induced AE leading to cessation of therapy

\begin{tabular}{lllllll}
\hline Adverse event & Patients, $n(\%)$ & $\begin{array}{l}\text { Median time with thio- } \\
\text { purines, days (IQR) }\end{array}$ & $\begin{array}{l}\text { Rechallenge same } \\
\text { thiopurine, } n(\%)\end{array}$ & $\begin{array}{l}\text { Reoccurrence } \\
\text { AE, } n(\%)\end{array}$ & $\begin{array}{l}\text { Rechallenge second } \\
\text { thiopurine, } n(\%)\end{array}$ & $\begin{array}{l}\text { Reoccur- } \\
\text { rence AE, } \\
n(\%)\end{array}$ \\
\hline Severe leukopenia & $2(4.0)$ & $31-514^{\dagger}$ & $1(50.0)$ & $1(100)$ & 0 & 0 \\
Thrombocytopenia & $1(2.0)$ & 161 & $1(100)$ & 0 & 0 & 0 \\
Myelotoxicity & $2(4.0)$ & $118-399^{\dagger}$ & 0 & 0 & $1(20.0)$ & 0 \\
Hepatotoxicity & $5(10.0)$ & $59(32-976)$ & $2(40.0)$ & $2(20.0)$ & $2(16.7)$ & $5(31.3)$ \\
Flu-like symptoms & $12(24.0)$ & $82(27-181)$ & $10(83.3)$ & 0 & 0 & 0 \\
GI symptoms & $16(32.0)$ & $40(14-128)$ & $2(12.5)$ & 0 & $1(100)$ & 0 \\
Pancreatitis & $8(16.0)$ & $21(16-26)$ & 0 & 0 & 0 & 0 \\
Alopecia & $2(4.0)$ & $119-1872^{\dagger}$ & $1(50.0)$ & $1(100)$ & 0 & 0 \\
Shingles & $1(2.0)$ & 321 & 0 & 0 & 0 \\
Rhabdomyolysis & $1(2.0)$ & 409 & & 0 & 0 \\
\hline
\end{tabular}

$A E$ adverse event, $G I$ gastrointestinal

$\dagger$ Median time is not applicable. The range is used to present the time of onset of severe leukopenia, myelotoxicity and alopecia $(\mathrm{n}=2)$

Rechallenge with the same thiopurine comprises rechallenge with azathioprine in 17 patients and rechallenge with mercaptopurine in one patient. Rechallenge with a second thiopurine comprises a switch to mercaptopurine in six patients and a switch to tioguanine in 2 patients

\section{Potential Predictive Factors for Adverse Events Leading to Cessation of Therapy}

Thirty-eight patients developed grade 1-3 AE within six months after initiation of thiopurines, leading to cessation of therapy. Univariate logistic regression analyses showed no significant effects of age at diagnosis, gender, and disease phenotype between the $\mathrm{AE}$ and non-AE group (Online Resource 1). In 16 out of 38 patients (42.1\%) who developed an $\mathrm{AE}$ within the first 6 months after initiation of thiopurines, versus 40 out of 162 patients $(24.7 \%)$ with a follow-up of 6 months in the non-AE group, concentrations of 6-TGN and 6-MMP were measured. No significant differences of 6-TGN and 6-MMP concentrations were found between these two groups (Online Resource 1). Since none of the variables reached a statistical significance of $p<0.2$, a multivariate regression analysis was not performed.
Fig. 1 Kaplan-Meier curve of patients with IBD who developed AE leading to therapy cessation. The $\mathrm{X}$-axis represents the time in months. The Y-axis represents the probability of discontinuing treatment due to AE. The cumulative incidence of $\mathrm{AE}$ was $13.5 \%, 16.7 \%$, $17.3 \%$, and $21.8 \%$ at $3,6,12$, and 24 months of therapy, respectively

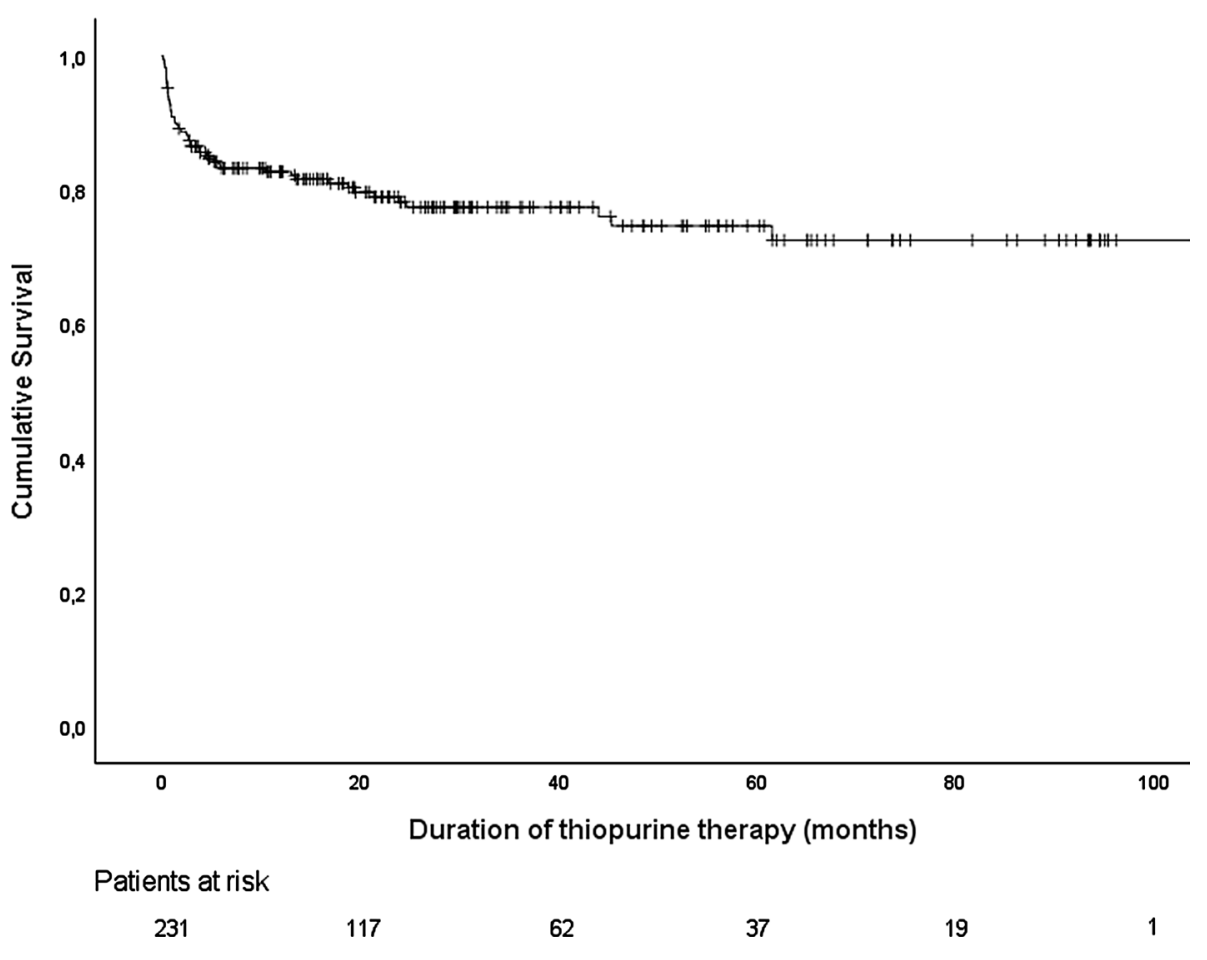


Table 5 Spearman's correlations between erythrocyte concentrations of 6-TGN and 6-MMP and hematological indices and liver tests

\begin{tabular}{lll}
\hline & 6-TGN Correlation $[r(p)]$ & 6-MMP Correlation $[r(p)]$ \\
\hline $\mathrm{Hb}$ & $0.025(p=0.62)$ & $-0.010(p=0.85)$ \\
$\mathrm{WBC}$ & $-0.168(p=0.001)^{* *}$ & $-0.068(p=0.18)$ \\
$\mathrm{MCV}$ & $0.417(p<0.0005)^{* *}$ & $-0.040(p=0.54)$ \\
$\mathrm{ANC}$ & $-0.177(p=0.004)^{* *}$ & $-0.015(p=0.81)$ \\
PC & $-0.058(p=0.25)$ & $0.058(p=0.26)$ \\
ALT & $-0.099(p=0.05)$ & $0.104(p=0.049)^{*}$ \\
AST & $-0.080(p=0.27)$ & $0.113(p=0.13)$ \\
AP & $0.037(p=0.68)$ & $-0.120(p=0.20)$ \\
GGT & $0.115(p=0.11)$ & $0.152(p=0.040)^{*}$ \\
\hline
\end{tabular}

*Statistically significant at the level $p<0.05$

${ }^{* *}$ Statistically significant at the level $p<0.01$

6-TGN 6-thioguanine nucleotides, 6-MMP 6-methylmercaptopurine, $H b$ haemoglobin, $W B C$ white blood cell, $M C V$ mean corpuscular volume, $A N C$ absolute neutrophil count, $P C$ platelet count, $A L T$ alanine aminotransferase, $A S T$ aspartate aminotransferase, $A P$ alkaline phosphatase, GGT gamma-glutamyltranspeptidase

\section{Effect of Thiopurine Metabolites on Hematological Indices and Liver Tests}

Concentrations of 6-TGN and 6-MMP were measured 469 times in 164 unique patients. In 430 measurements, determination of 6-TGN and 6-MMP was combined with assessment of either hematological indices $(n=34)$ or liver tests $(n=4)$, or both $(n=382)$ within predefine time interval. In 10 cases, 6-TGN and 6-MMP concentrations were undetectable and related laboratory measurements were therefore excluded from analysis. The median 6-TGN concentration was $480 \mathrm{pmol} / 8 \times 10^{8} \mathrm{RBC}$ [IQR, 330-690] and the median 6 -MMP concentration was $1400 \mathrm{pmol} / 8 \times 10^{8} \mathrm{RBC}[\mathrm{IQR}$, 580-3375]. There was a statistically significant, positive correlation between 6-TGN concentrations and MCV. 6-TGN concentrations were negatively correlated with WBC count and neutrophil count. A weak positive correlation was found between 6-MMP concentrations and ALT and GGT (Table 5).

Laboratory data regarding WBC, PC or ANC were available in 412 out of 420 measurements (98\%). In 17 cases with myelosuppression, concentrations of 6-TGN (median 530 vs. $480 \mathrm{pmol} / 8 \times 10^{8} \mathrm{RBC}, p=0.33$ ) and concentrations of 6-MMP (median 1900 vs. $1400 \mathrm{pmol} / 8 \times 10^{8} \mathrm{RBC}, p=0.20$ ) were slightly higher in patients with myelosuppression as compared to patients without myelosuppression, however this difference did not reach statistical significance. Incidence of myelosuppression was not significantly higher in the group with 6-TGN concentrations outside the therapeutic range (>600 pmol/ $\left.8 \times 10^{8} \mathrm{RBC}\right)$ as compared to patients with 6-TGN concentrations within the therapeutic range (Table 6).

Liver tests were available in 386 measurements (92\%). Hepatotoxicity was observed in 20 cases (5\%). In these patients, there were no differences in median 6-MMP concentrations $(p=0.65)$ or 6-TGN concentrations $(p=0.70)$ as compared to patients without hepatotoxicity. In all patients with hepatotoxicity, 6-MMP concentrations were below the toxic reference value $\left(<5700 \mathrm{pmol} / 8 \times 10^{8} \mathrm{RBC}\right)$. Amongst the patients with 6-MMP concentrations exceeding the reference value ( $\left.>5700 \mathrm{pmol} / 8 \times 10^{8} \mathrm{RBC}\right)$, the incidence of myelosuppression was significantly higher compared with patients with 6-MMP concentrations below the toxic
Table 6 Incidence of myelosuppression across reference values of 6-TGN and 6-MMP concentrations

\begin{tabular}{lll}
\hline Thiopurine metabolites & Myelosuppression $(n=17)$ & $\begin{array}{l}\text { No myelo- } \\
\text { suppression } \\
(n=375)^{\dagger}\end{array}$ \\
\hline $6-\mathrm{MMP}(n=392)$ & & \\
$6-\mathrm{MMP}>5700 \mathrm{pmol} / 8 \times 10^{8} \mathrm{RBC}(n=41)$ & $12.2 \%(n=5)$ & $87.8 \%(n=36)$ \\
6-MMP $<5700 \mathrm{pmol} / 8 \times 10^{8} \mathrm{RBC}(n=351)$ & $3.4 \%(n=12)$ & $96.6 \%(n=339)$ \\
$p$-value & 0.023 & \\
6-TGN $(n=411)$ & & $94.3 \%(n=132)$ \\
6-TGN $>600 \mathrm{pmol} / 8 \times 10^{8} \mathrm{RBC}(n=140)$ & $3.7 \%(n=8)$ & $96.7 \%(n=262)$ \\
6-TGN $<600 \mathrm{pmol} / 8 \times 10^{8} \mathrm{RBC}(n=271)$ & 0.30 & $80.0 \%(n=12)$ \\
$p$ value & $20.0 \%(n=3)$ & $96.3 \%(n=363)$ \\
6-TGN/6-MMP both abnormal $(n=15)$ & $3.7 \%(n=14)$ & \\
$\ddagger$ 6-TGN/6-MMP normal $(n=377)$ & 0.022 & \\
$p$ value & & \\
\hline
\end{tabular}

6-TGN 6-thioguanine nucleotides, 6-MMP 6-methylmercaptopurine, $R B C$ red blood cell

${ }^{\dagger} 392$ available 6-MMP or 6-TGN/6-MMP measurements, no myelosuppression: $n=375$

411 available 6-TGN measurements, no myelosuppression: $n=394$

${ }^{\ddagger}$-TGN $>600 \mathrm{pmol} / 8 \times 10^{8} \mathrm{RBC}$ and $6-\mathrm{MMP}>5700 \mathrm{pmol} / 8 \times 10^{8} \mathrm{RBC}$ 
Fig. 2 Kaplan-Meier curve of ongoing thiopurine use in the patients who tolerated thiopurine therapy. The Y-axis represents the percentage of patients still using thiopurines at different time points. The percentage of patients still using thiopurines was $97.8 \%, 92.0 \%$, $84.3 \%, 69.2 \%$, and $37.0 \%$ at 3 , $6,12,24$, and 60 months following initiation, respectively

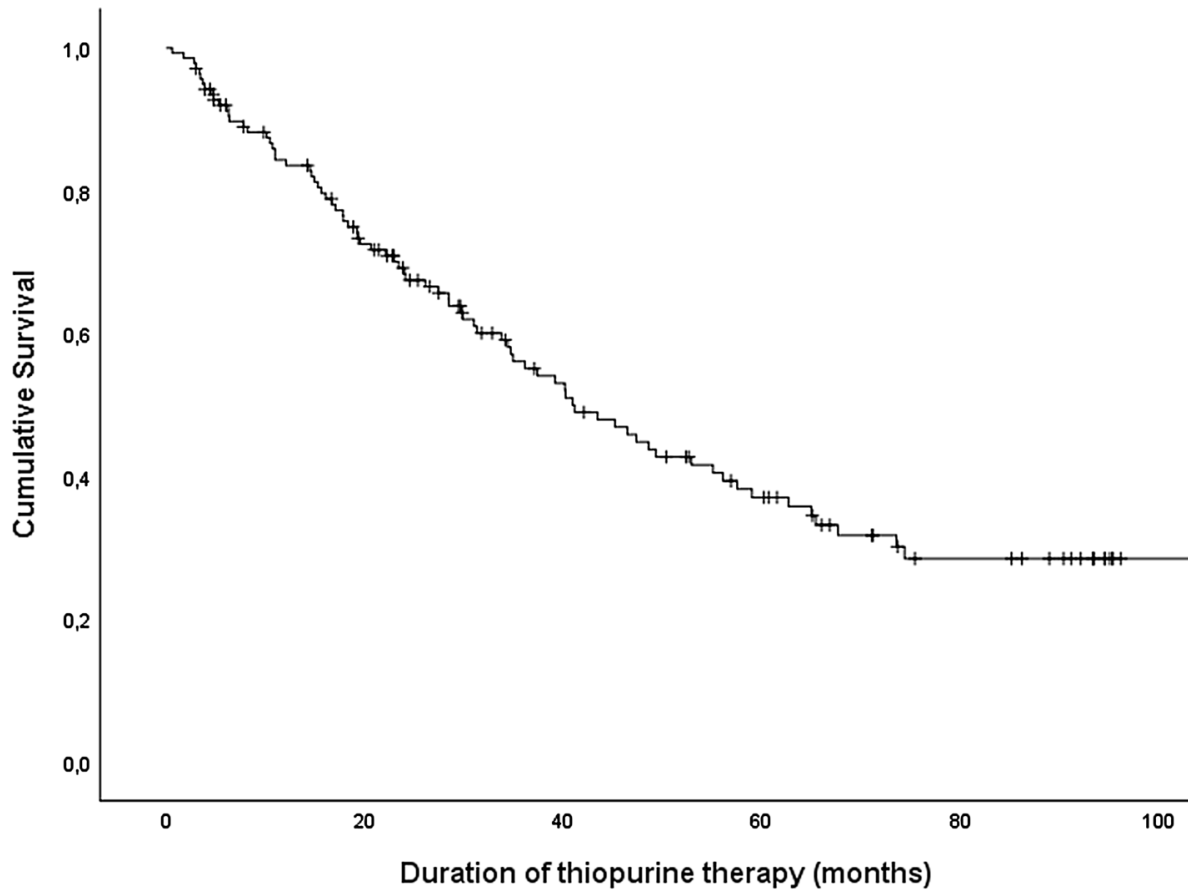

Patients at risk

139
90
52
32
16 reference value. The incidence of myelosuppression across reference values of 6-TGN and 6-MMP concentrations is depicted in Table 6.

\section{Drug Survival}

To determine the overall drug survival, we excluded 92 patients: 50 patients who ceased thiopurine therapy due to $\mathrm{AE}$, and 42 patients with combination therapy of thiopurines and anti-TNF $\alpha$ agents in context of top-down treatment strategy. Amongst the remaining 141 patients who tolerated thiopurine therapy, 57.4\% $(n=81)$ ceased thiopurines, median duration of therapy was 23.4 months [IQR, 11.0-40.9]. Reasons for cessation included clinical refractoriness (53.1\%), sustained clinical remission (14.8\%), at patients' or parents' own request (22.2\%), or others reasons such as pregnancy $(6.2 \%)$. In three patients, the reason for cessation was unknown. The calculated drug survival is depicted in Fig. 2. In the group of patients who ceased thiopurine therapy due to clinical refractoriness $(n=43)$, infliximab was initiated as additional therapy in 13 patients (30.2\%). These patients received a combination of infliximab and thiopurines, until thiopurine therapy was routinely ceased after 6-12 months. Amongst the 31 patients who continued thiopurine monotherapy until the end of follow-up, fecal calprotectin levels were available in 16 out of 31 patients $(51.6 \%)$ within 3 months of the last follow-up visit. Twelve out of 16 patients $(75 \%)$ were considered in biochemical remission, based on a fecal calprotectin value of $<250 \mu \mathrm{g} / \mathrm{mg}$.

\section{Discussion}

The present study aimed to determine incidence of thiopurine-induced $\mathrm{AE}$ resulting in cessation of therapy in a large cohort of children. Of 233 included pediatric patients, $22 \%$ discontinued thiopurine therapy due to thiopurine-induced AE. Approximately $50 \%$ of patients were rechallenged and $70 \%$ of these patients tolerated this. Only $37 \%$ of children were still on thiopurines after 5 years.

Around $20 \%$ of patients developed grade $1-3$ AE in our cohort, which is comparable to rates reported in other pediatric studies (15-22\%) [10-12]. In a study by Hindorf et al. [10], including 79 pediatric patients with IBD, $15 \%$ had thiopurine-induced AE leading to therapy cessation or dose reduction. The reported lower percentage might be explained by possible limited access to alternative therapeutic options for pediatric IBD in that study period (1997-2003). Nowadays, treating physicians might opt for an earlier switch to anti-TNF $\alpha$ agents, even in case of mild thiopurine-induced AE. A more recent study in pediatric patients with IBD $(n=216)$ [12], showed a discontinuation rate of $22 \%$ due to thiopurine-induced adverse effects, which is consistent with our findings. 
In the present study, $70 \%$ tolerated a rechallenge with thiopurines after discontinuation of treatment due to AE. A study by Chaparro et al. [20], found a comparable success percentage following rechallenge of $60 \%$ in adults with IBD. In addition, $7 \%$ of our pediatric IBD cohort switched from AZA to a second thiopurine agent due to AE, and $63 \%$ of these patients tolerated this. Percentages varying between 42 and $73 \%$ were reported regarding adults with IBD who tolerated MP after AZA intolerance [14, 15, 21-23]. Mercaptopurine tolerance was observed in adults with IBD with previously reported gastrointestinal intolerance, hepatotoxicity, flu-like symptoms and arthralgia/myalgia (during AZA treatment) $[14,15,21,23]$. In our cohort, MP was not prescribed in patients with AZA-induced pancreatitis, since we considered this a contraindication for another thiopurine agent. Previous case series in children with CD [24, 25], however, have described MP tolerance after AZA-induced pancreatitis, challenging the assumption that this is an absolute contraindication. It has been hypothesized that the AZA imidazole component, which is released when AZA is converted to MP, is partly responsible for early intolerance [26]. An explanation for the high success rates following rechallenge might be that mild $\mathrm{AE}$, including gastrointestinal intolerance and flu-like symptoms, are transient and could resolve without any intervention. Gastrointestinal symptoms and flu-like symptoms could also be a consequence of unrecognized infections. Additionally, gastrointestinal intolerance, flu-like symptoms, and alopecia, often considered as thiopurine-induced $\mathrm{AE}$, could also be due to IBD disease activity.

In this study, 6-TGN concentrations were negatively correlated with WBC count and neutrophil count and positively correlated with MCV, while 6-MMP concentrations were positively correlated with ALT and GGT. These findings probably reflect the association between myelosuppression and high concentrations of 6-TGN [1], as well as the association between elevated 6-MMP and hepatotoxicity [27]. However, in our cohort, we did not observe a correlation between 6-MMP concentrations exceeding the toxic reference value $\left(>5700 \mathrm{pmol} / 8 \times 10^{8} \mathrm{RBC}\right)$ and hepatotoxicity. A previous study in pediatric patients with IBD did also not find 6-MMP concentrations exceeding the toxic reference value in patients with hepatotoxicity [28]. In contrast to a previous published finding [27], we did not observe an association between myelosuppression and higher 6-TGN concentrations. The lack of association between 6-TGN and 6-MMP concentrations and the adverse effects of myelosuppression and hepatotoxicity may relate to the small number of patients with these events. On the contrary, a study by Duley et al. [29], revealed the problems in measuring 6-TGN in erythrocytes which is not the ideal cell, and technical concerns about the validity of acid hydrolysis method of Dervieux. This may also explain why drop-out of patients due to myelosuppression could not be predicted by measuring 6-TGN concentrations. In the present study, we observed that the incidence of myelosuppression was significantly higher (12\% vs. $3 \%$ ) in the cases with 6-MMP concentrations $>5700 \mathrm{pmol} / 8 \times 10^{8} \mathrm{RBC}$ compared to 6-MMP concentrations below this reference value, respectively. This is in line with a previous study by Wong et al. [30], showing that the predictive value for developing leukopenia of 6-MMP metabolites is similar to that of 6-TGN metabolites. Additionally, they found an increased risk of leukopenia in patients with both 6-MMP and 6-TGN concentrations exceeding the defined threshold, comparable to our findings. These data suggest that 6-MMP and its ribonucleotides can inhibit purine de novo synthesis, resulting in inhibition of DNA formation [31].

In our cohort of pediatric patients, only $37 \%$ of patients still used thiopurine therapy after 5 years. Approximately $50 \%$ ceased therapy due to clinical refractoriness, and in $30 \%$ of these patients, infliximab was already administered. A previous study by van Hoeve et al. [11], showed that only $32 \%$ of children with IBD treated with immunosuppressive agents, mainly thiopurines, remained free of biologics or surgery 5-years after diagnosis. Around 20\% of patients ceased thiopurine therapy at patients' or parents' own request, mostly due to non-adherence. Non-adherence to oral medication is a well-known problem in adolescents, with non-adherence prevalence rates ranging from 2 to $93 \%$ [32].

The strength of this study is that we report on the largest pediatric IBD cohort so far regarding incidence of thiopurine-induced $\mathrm{AE}$, related to thiopurine metabolites and biochemical abnormalities. The most important limitation is the retrospective design of this study, and consequently lack of standardization of collected data. Consequently, any potential AE not resulting in cessation of thiopurine therapy has not been recorded in a standardized matter in patients' files, possibly leading to bias, and therefore not included in this study. Since metabolite measurement was not performed in a standardized matter, timing and reason for measuring metabolites may have led to selection bias. Additionally, TPMT genotyping and activity assessments were not routinely assessed prior to initiation of thiopurines. Another limitation might be the drug interactions between thiopurines and other coadministered drugs that were not analyzed. Patients with reintroduction of thiopurine therapy in case of AE probably infer a selection bias, as there were no standardized criteria for reintroduction of thiopurine therapy after AE. Reintroduction was commonly performed in mild AE and mainly dependent on physician's judgement, possibly resulting in an overestimated success percentage of rechallenge following $\mathrm{AE}$, however, these data reflect general practice.

In conclusion, in a real-life pediatric IBD cohort, $22 \%$ discontinued thiopurines due to $\mathrm{AE}$. A rechallenge or switch to MP can be an effective strategy after AE. This was not studied, however, in patients with pancreatitis and severe myelotoxicity. Thiopurine metabolite concentrations significantly 
affect hematological indices and liver tests and they should therefore not exceed reference values. Only $37 \%$ of children were still on thiopurines after 5 years, illustrating that efficacy of thiopurines as long-term maintenance therapy seems limited in clinical practice. A reassessment of the use of thiopurines, including pre-exposure genotyping and tight monitoring of metabolites, in pediatric IBD is warranted.

Supplementary Information The online version contains supplementary material available at https://doi.org/10.1007/s10620-021-06836-3.

Acknowledgments There are no additional acknowledgments.

Author's contribution JJ conceptualized and designed this study, coordinated and supervised data collection, carried out the statistical analyses, drafted the initial version of this paper, and reviewed and revised this paper. $\mathrm{CP}$ collected data, carried out the statistical analyses, drafted the initial version of this paper and reviewed this paper. $\mathrm{NdB}$ and $\mathrm{TdM}$ conceptualized and designed this study, coordinated and supervised data collection, and critically reviewed this paper for important intellectual content. HB collected data and critically reviewed this paper for important intellectual content. JvL, MvW and MB critically reviewed this paper for important intellectual content. All authors approved the final version of the article, including the authorship list.

Funding The authors received no financial support for the research, authorship, and/or publication of this article.

Data availability The authors confirm that the data supporting the findings of this study are available within the article.

\section{Compliance with Ethical Standards}

Conflicts of interest $\mathrm{NdB}$ has served as a speaker for AbbVie and MSD and has served as consultant and principal investigator for TEVA Pharma BV and Takeda. He has received a (unrestricted) research grant from Dr. Falk, TEVA Pharma BV, MLDS and Takeda. JvL reports consulting, travel and/or speaker fees and research support from AbbVie, Janssen, Nestlé Health Science, Novalac, Pfizer, Merck, $\mathrm{P} \& \mathrm{G}, \mathrm{GSK}$, Illumina, Otsuka. JJ, CP, HB, MvW, MB, and TdM have nothing to declare.

Ethics approval The study protocol was in accordance with the ethical guide-lines of the 1975 Declaration of Helsinki and was approved on January 2020 by the local ethics committee of the Amsterdam UMC, location VUmc, under file number 2020.026.

Consent to participate We have made use of an opt-out consent procedure. Parent(s)/guardian(s) and children (in case of age $>12$ years) had the opportunity to file an objection stating that they do not wish for their child/themselves to participate.

Open Access This article is licensed under a Creative Commons Attribution-NonCommercial 4.0 International License, which permits any non-commercial use, sharing, adaptation, distribution and reproduction in any medium or format, as long as you give appropriate credit to the original author(s) and the source, provide a link to the Creative Commons licence, and indicate if changes were made. The images or other third party material in this article are included in the article's Creative Commons licence, unless indicated otherwise in a credit line to the material. If material is not included in the article's Creative Commons licence and your intended use is not permitted by statutory regulation or exceeds the permitted use, you will need to obtain permission directly from the copyright holder. To view a copy of this licence, visit http://creativecommons.org/licenses/by-nc/4.0/.

\section{References}

1. Ruemmele FM, Veres G, Kolho KL et al. Consensus guidelines of ECCO/ESPGHAN on the medical management of pediatric Crohn's disease. J Crohns Colitis. 2014;8:1179-1207. https://doi. org/10.1016/j.crohns.2014.04.005.

2. Turner D, Ruemmele FM, Orlanski-Meyer E et al. Management of Paediatric Ulcerative Colitis, Part 1: Ambulatory Care-An Evidence-based Guideline From European Crohn's and Colitis Organization and European Society of Paediatric Gastroenterology, Hepatology and Nutrition. J Pediatr Gastroenterol Nutr. 2018;67:257-291. https://doi.org/10.1097/mpg.000000000000203 5.

3. Mogensen DV, Brynskov J, Ainsworth MA, Nersting J, Schmiegelow K, Steenholdt C. A Role for Thiopurine Metabolites in the Synergism Between Thiopurines and Infliximab in Inflammatory Bowel Disease. J Crohns Colitis. 2018;12:298-305. https://doi. org/10.1093/ecco-jcc/jjx149.

4. Hyams JS, Lerer T, Mack D et al. Outcome following thiopurine use in children with ulcerative colitis: a prospective multicenter registry study. Am J Gastroenterol. 2011;106:981-987. https:// doi.org/10.1038/ajg.2010.493.

5. Riello L, Talbotec C, Garnier-Lengline $\mathrm{H}$ et al. Tolerance and efficacy of azathioprine in pediatric Crohn's disease. Inflamm Bowel Dis. 2011;17:2138-2143. https://doi.org/10.1002/ibd.21612.

6. Markowitz J, Grancher K, Kohn N, Lesser M, Daum F. A multicenter trial of 6-mercaptopurine and prednisone in children with newly diagnosed Crohn's disease. Gastroenterology. 2000;119:895-902. https://doi.org/10.1053/gast.2000.18144.

7. Panes J, Lopez-Sanroman A, Bermejo F et al. Early azathioprine therapy is no more effective than placebo for newly diagnosed Crohn's disease. Gastroenterology. 2013;145:e1. https://doi. org/10.1053/j.gastro.2013.06.009.

8. Cosnes J, Bourrier A, Laharie D et al. Early administration of azathioprine vs conventional management of Crohn's Disease: a randomized controlled trial. Gastroenterology. 2013;145:e14-e15. https://doi.org/10.1053/j.gastro.2013.04.048.

9. Ashworth LA, Billett A, Mitchell P, Nuti F, Siegel C, Bousvaros A. Lymphoma risk in children and young adults with inflammatory bowel disease: analysis of a large single-center cohort. Inflamm Bowel Dis. 2012;18:838-843. https://doi.org/10.1002/ ibd. 21844 .

10. Hindorf U, Lindqvist M, Hildebrand H, Fagerberg U, Almer $\mathrm{S}$. Adverse events leading to modification of therapy in a large cohort of patients with inflammatory bowel disease. Aliment Pharmacol Ther. 2006;24:331-342. https://doi.org/10.111 1/j.1365-2036.2006.02977.x.

11. van Hoeve K, Hoffman I, D'Hoore A, Ferrante M, Vermeire S. Long-term outcome of immunomodulator use in pediatric patients with inflammatory bowel disease. Dig Liver Dis. 2019. https://doi. org/10.1016/j.dld.2019.09.008.

12. Spencer E, Norris E, Williams C, Dubinsky MC. The Impact of Thiopurine Metabolite Monitoring on the Durability of Thiopurine Monotherapy in Pediatric IBD. Inflamm Bowel Dis. 2019;25:142-149. https://doi.org/10.1093/ibd/izy216.

13. Chun JY, Kang B, Lee YM, Lee SY, Kim MJ, Choe YH. Adverse events associated with azathioprine treatment in korean pediatric inflammatory bowel disease patients. Pediatr Gastroenterol 
Hepatol Nutr. 2013;16:171-177. https://doi.org/10.5223/ pghn.2013.16.3.171.

14. Kennedy NA, Rhatigan E, Arnott ID et al. A trial of mercaptopurine is a safe strategy in patients with inflammatory bowel disease intolerant to azathioprine: an observational study, systematic review and meta-analysis. Aliment Pharmacol Ther. 2013;38:1255-1266. https://doi.org/10.1111/apt.12511.

15. Hindorf U, Johansson M, Eriksson A, Kvifors E, Almer SH. Mercaptopurine treatment should be considered in azathioprine intolerant patients with inflammatory bowel disease. Aliment Pharmacol Ther. 2009;29:654-661. https://doi.org/10.111 1/j.1365-2036.2008.03925.x.

16. Levine A, Koletzko S, Turner D et al. ESPGHAN revised porto criteria for the diagnosis of inflammatory bowel disease in children and adolescents. J Pediatr Gastroenterol Nutr. 2014;58:795806. https://doi.org/10.1097/mpg.0000000000000239.

17. Levine A, Griffiths A, Markowitz J et al. Pediatric modification of the Montreal classification for inflammatory bowel disease: the Paris classification. Inflamm Bowel Dis. 2011;17:1314-1321. https ://doi.org/10.1002/ibd.21493.

18. Trotti A, Colevas AD, Setser A et al. CTCAE Development of a comprehensive grading system for the adverse effects of cancer treatment. Seminars Radiat Oncol 2003;13:176-181

19. Dervieux T, Boulieu R. Simultaneous determination of 6-thioguanine and methyl 6-mercaptopurine nucleotides of azathioprine in red blood cells by HPLC. Clin Chem. 1998;44:551-555

20. Chaparro M, Ordas I, Cabre E et al. Safety of thiopurine therapy in inflammatory bowel disease: long-term follow-up study of 3931 patients. Inflamm Bowel Dis. 2013;19:1404-1410. https:// doi.org/10.1097/MIB.0b013e318281f28f.

21. Lees CW, Maan AK, Hansoti B, Satsangi J, Arnott ID. Tolerability and safety of mercaptopurine in azathioprine-intolerant patients with inflammatory bowel disease. Aliment Pharmacol Ther. 2008;27:220-227. https://doi.org/10.111 1/j.1365-2036.2007.03570.x.

22. Domenech E, Nos P, Papo M, Lopez-San Roman A, GarciaPlanella E, Gassull MA. 6-mercaptopurine in patients with inflammatory bowel disease and previous digestive intolerance of azathioprine. Scand J Gastroenterol. 2005;40:52-55. https:// doi.org/10.1080/00365520410009492.

23. Meijer B, Seinen ML, Leijte NN, Mulder CJ, van Bodegraven AA, de Boer NK. Clinical Value of Mercaptopurine After Failing Azathioprine Therapy in Patients With Inflammatory Bowel Disease. Ther Drug Monit. 2016;38:463-470. https://doi.org/10.1097/ ftd.0000000000000312.
24. Ledder OD, Lemberg DA, Ooi CY, Day AS. Are thiopurines always contraindicated after thiopurine-induced pancreatitis in inflammatory bowel disease? J Pediatr Gastroenterol Nutr. 2013;57:583-586. https://doi.org/10.1097/MPG.0b013e3182 9f16fc.

25. Gallego-Gutierrez S, Navas-Lopez VM, Kolorz M et al. Successful Mercaptopurine Usage despite Azathioprine-Induced Pancreatitis in Paediatric Crohn's Disease. J Crohns Colitis. 2015;9:676679. https://doi.org/10.1093/ecco-jcc/jjv086.

26. McGovern DP, Travis SP, Duley J, el Shobowale-Bakre M, Dalton HR. Azathioprine intolerance in patients with IBD may be imidazole-related and is independent of TPMT activity. Gastroenterology. 2002;122:838-839. https://doi.org/10.1053/gast.2002.32124.

27. Dubinsky MC, Lamothe S, Yang HY et al. Pharmacogenomics and metabolite measurement for 6-mercaptopurine therapy in inflammatory bowel disease. Gastroenterology. 2000;118:705-713

28. Ooi CY, Bohane TD, Lee D, Naidoo D, Day AS. Thiopurine metabolite monitoring in paediatric inflammatory bowel disease. Aliment Pharmacol Ther. 2007;25:941-947. https://doi.org/10.1 111/j.1365-2036.2007.03278.x.

29. Duley JA, Florin TH. Thiopurine therapies: problems, complexities, and progress with monitoring thioguanine nucleotides. Ther Drug Monit. 2005;27:647-654. https://doi.org/10.1097/01. ftd.0000169061.52715.3e.

30. Wong DR, Coenen MJ, Vermeulen SH et al. Early Assessment of thiopurine metabolites identifies patients at risk of thiopurineinduced Leukopenia in inflammatory bowel Disease. J Crohns Colitis. 2017;11:175-184. https://doi.org/10.1093/ecco-jcc/jjw13 0 .

31. Coulthard SA, Hogarth LA, Little M et al. The effect of thiopurine methyltransferase expression on sensitivity to thiopurine drugs. Mol Pharmacol. 2002;62:102-109. https://doi.org/10.1124/ mol.62.1.102.

32. Spekhorst LM, Hummel TZ, Benninga MA, van Rheenen PF, Kindermann A. Adherence to oral maintenance treatment in adolescents with inflammatory bowel disease. J Pediatr Gastroenterol Nutr. 2016;62:264-270. https://doi.org/10.1097/mpg.0000000000 000924.

Publisher's Note Springer Nature remains neutral with regard to jurisdictional claims in published maps and institutional affiliations.

\section{Authors and Affiliations}

\section{Jasmijn Z. Jagt ${ }^{1} \cdot$ Christine D. Pothof $^{1} \cdot$ Hans J. C. Buiter ${ }^{2} \cdot$ Johan E. van Limbergen $^{3} \cdot$ Michiel P. van Wijk $^{1,3}$. Marc A. Benninga ${ }^{3}$. Nanne K. H. de Boer ${ }^{4}$-Tim G. J. de Meij ${ }^{1,3}$}

Christine D. Pothof

kirstenpothof@gmail.com

Hans J. C. Buiter

hjc.buiter@amsterdamumc.nl

Johan E. van Limbergen

j.e.vanlimbergen@amsterdamumc.nl

Michiel P. van Wijk

m.vanwijk@amsterdamumc.nl

Marc A. Benninga

m.a.benninga@amsterdamumc.nl
Nanne K. H. de Boer

khn.deboer@amsterdamumc.nl

Tim G. J. de Meij

t.demeij@amsterdamumc.nl

1 Department of Pediatric Gastroenterology, Emma Children's Hospital, Amsterdam, UMC, Vrije Universiteit Amsterdam, 1105 AZ Amsterdam, The Netherlands

2 Department of Clinical Pharmacology and Pharmacy, Amsterdam, UMC, Vrije Universiteit Amsterdam, 1105 AZ Amsterdam, The Netherlands 
3 Department of Pediatric Gastroenterology, UMC, Emma Children's Hospital, Amsterdam, Academic Medical Centre, 1081 HV Amsterdam, The Netherlands

4 Department of Gastroenterology and Hepatology, Amsterdam Gastroenterology and Metabolism Research
Institute, Amsterdam, UMC, Vrije Universiteit Amsterdam, 1081 HV Amsterdam, The Netherlands 